\title{
Crenças e atitudes do falar do outro: Percepções linguísticas de informantes universitários sobre o falar da Baixada Cuiabana
}

\author{
Rhafaela Rico Bertolino Beriula (UNEMAT)* \\ https://orcid.org/0000-0002-9027-1968
}

\section{Resumo:}

No cenário sociolinguístico mato-grossense, a discussão acerca das diversidades linguísticas abre espaço para pesquisas sobre as variedades linguísticas e o falar do outro. Com vista em contribuir com tais estudos, este trabalho tem o objetivo de investigar as crenças e atitudes de informantes universitários juarenses sobre os valores socioculturais da comunidade de fala da Baixada Cuiabana, tendo como fenômeno teórico a alternância das fricativas e africadas. Para tanto, este estudo segue a perspectiva teórica da Sociolinguística Variacionista de terceira onda. A hipótese levantada é a de que os informantes universitários avaliariam a comunidade de fala da Baixada Cuiabana como uma variação linguística estigmatizada. Optou-se por uma pesquisa qualitativa, tendo como método o teste de percepção de diferencial semântico, conhecido como matched guise, de Lambert e Lambert (1972). 0 corpus foi constituído por doze informantes universitários nascidos na cidade de Juara vinculados a Universidade do Estado de Mato Grosso (UNEMAT). 0 teste de percepção de diferencial semântico adaptado da técnica matched guise, possibilitou analisar as percepções linguísticas dos informantes universitários juarenses, que teve como resultado a comprovação da hipótese levantada: os informantes universitários avaliariam a comunidade de fala da Baixada Cuiabana como uma variação linguística estigmatizada.

Palavras-chave: Falar do outro; Baixada Cuiabana; crenças e atitudes; Sociolinguística Variacionista.

\section{Abstract:}

\section{Beliefs and attitudes of the speech of the other: Linguistic perceptions of university informants about}

* Graduada em Pedagogia pela Universidade do Estado de Mato Grosso (UNEMAT) em 2014, Especialista em Docência no Ensino Superior e na Educação de Jovens e Adultos (EJA) pela Faculdade Venda Nova Do Imigrante (FAVENI) em 2017, Mestra em Letras pelo Programa de Pós-Graduação em Letras (PPG Letras) 2018/2020, ofertado pela UNEMAT no Câmpus Universitário de Sinop. Integrante do Grupo de Pesquisa Educação Científico-tecnológica e Cidadania (ECTeC). Lattes: http://lattes.cnpq.br/3646144874581689. E-mail: rhafaela.rico@gmail.com 


\section{the speech of Baixada Cuiabana}

In the socio-linguistic scenario of Mato Grosso state, the discussion about linguistic diversity opens space for research on linguistic varieties and the speech of the other. In order to contribute to such studies, this work aims to investigate the beliefs and attitudes of university informants from Juara city about the socio-cultural values of the Baixada Cuiabana speech community, having as a theoretical phenomenon the alternation of fricatives and affricates. So that, this study follows the theoretical perspective of the third wave Variationist Sociolinguistics. The hypothesis raised is that the university informants would evaluate the Baixada Cuiabana speech community as a stigmatized linguistic variation. It was done a qualitative research, using the semantic differential perception test method, known as matched guise, by Lambert and Lambert (1972). The corpus was constituted of twelve university informants born in Juara city, in the Mato Grosso state, linked to the State University of Mato Grosso (UNEMAT). The semantic differential perception test adapted from the matched guise technique, made it possible to analyze the linguistic perceptions of the university informants from Juara, which resulted in the confirmation of the hypothesis raised: university informants would evaluate the Baixada Cuiabana speech community as a stigmatized linguistic variation.

Keywords: Speech of the other; Baixada Cuiabana; beliefs and attitudes; Variationist Sociolinguistics.

\section{Considerações iniciais}

Para compreender a língua do outro não se pode deixar de evidenciar o processo de construção sócio histórico, uma vez que, todas as comunidades de fala passaram e continuarão passando por transformações sociais, culturais, políticas e econômicas, fatores que influenciam gradativamente as mudanças linguísticas.

Dessa forma, pode-se apontar que todas as línguas evoluem e se modificam com o tempo, adquirem características próprias de um falar que está, certamente, enraizado na história de formação de determinada comunidade. Assim, as mudanças/variedades dialetais que estão presentes na língua portuguesa utilizada no Brasil, do ângulo gramático-normativo, são completas em si, pois evidenciam o percurso único de construção que provocaram marcas próprias no falar.
Com o passar dos anos as mudanças linguísticas se apresentam mais vertiginosas, dada a atual conjuntura tecnológica e digital a qual o mundo se encontra. Segundo Blommaert e Rampton (2011), há duas causas para as mudanças linguísticas, a primeira é o fluxo de migrações que acontecem ao longo do mundo que leva ao efeito de mudanças nas demarcações demográficas e nos recursos comunicativos o que, por sua vez, resultam em mudanças e variedades nos falares. A segunda causa é a expansão das tecnologias de informação e comunicação, em razão de que as mídias tecnológicas acarretam um maior contato com o outro e a fala do outro, ocasionando inferências não só nas questões sociais e culturais, mas também, na língua.

Dada a perspectiva de Blommaert e Rampton (2011), no que concerne ao espa- 
ço linguístico de uma comunidade de fala, o contato com o outro através das migrações e das tecnologias digitais provocam, atualmente, mudanças significativas e aceleradas no falar de comunidades. Por exemplo, na Baixada Cuiabana, o contato direto e/ou indireto - digital - com o falar de outros vem propiciando variações linguísticas no falar daquele local.

Consoante a isso, tendo como perspectiva teórica a Sociolinguística Variacionista de terceira onda, o objetivo deste artigo é investigar, através de uma variação do teste de percepção de diferencial semântico, conhecido como matched guise, de Lambert e Lambert (1972), as crenças e atitudes de doze informantes universitários juarenses sobre a comunidade de fala da Baixada Cuiabana, localizada no estado de Mato Grosso (MT), tendo como fenômeno teórico a alternância das fricativas e africadas. Dos doze informantes, seis são do sexo/gênero feminino e seis do sexo/gênero masculino, sendo estes, nascidos na cidade de Juara, também no estado de MT.

Para desenvolver essa concepção, este artigo estrutura-se com o seguinte formato: no primeiro segmento apresenta-se a fundamentação teórica baseada na Sociolinguística Variacionista de terceira onda e, consoante a esse princípio, discutiremos sobre a constituição sócio-histórica da Baixada Cuiabana e as características linguísticas que foram construídas com o passar do tempo e que, hoje, passa por um processo de mudança, mediante o contato com a língua do outro - os migrantes - e a influência das tecnologias digitais. 0 segundo segmento discorrerá sobre a metodologia deste trabalho, assim como o método e os materiais utilizados para realizar o teste de percepção diferencial semântico. 0 terceiro segmento apresentará as análises dos resultados obti- dos durante a pesquisa e, por fim, o quarto segmento trará um efeito de fecho para este trabalho, buscando não concluir a pesquisa sobre as crenças e atitudes do falar da Baixada Cuiabana, mas sim, ampliar as discussões sobre a temática, contribuindo com as pesquisas sociolinguísticas no cenário mato-grossense.

\section{Fundamentação teórica}

Por se tratar de um país que possui protuberante extensão territorial, o Brasil possui em seu território - que é determinado e delimitado pelas relações de força e poder advindas desde o processo colonial - abundantes diferenças geográficas de relevo, clima, hidrografia, vegetação, entre outros aspectos que o caracterizam como um dos países mais ricos de biodiversidade do mundo. Neste imenso território, o Brasil também é caracterizado pelas intensas diferenças sociais e culturais que abarcam, do Caburaí ao Chuí, diversas comunidades linguísticas que possuem variações nas formas fonológicas, léxicas e gramaticais da forma de falar a língua portuguesa, que é a língua oficial e nacional do Brasil.

Nesse contexto brasileiro, encontra-se a Baixada Cuiabana, localizada no estado de Mato Grosso que possui uma variedade linguística interessante. De acordo com Cox (2005) e Lima (2018), ao longo dos anos, por causa das inferências culturais e sociais, o falar da Baixada Cuiabana foi se formulando até que, em determinado momento, se estabilizou. Contudo, hoje, volta a apresentar alterações/mudanças nas características linguísticas, por conta das migrações - que ainda ocorrem no estado -, da inferência das tecnologias digitais e dos preconceitos que sofrem. Tais causas apontam para a mudança das características linguísticas que a Baixada Cuiabana possuiu por um largo período. 
É interessante destacar que, segundo Calvet (2002), nenhum país possui uma língua oficial e nacional pura. Dentro de um sistema linguístico - que não deixa de ser político pois, como no Brasil, se encontra como língua obrigatória na Constituição -, há variáveis e variantes no falar de diversas comunidades, construídos a partir de suas condições sociais e históricas. Desta maneira, Calvet (2002, p. 68-69) aponta que “[...] os usos variam geograficamente, socialmente e historicamente, a norma espontânea varia da mesma maneira: não se tem as mesmas atitudes linguísticas na burguesia e na classe operária, em Londres ou na Escócia, hoje e cem anos atrás.”

A partir desta conjuntura, antes de estender a fundamentação das condições sócio -históricas que abrangem a Baixada Cuiabana e seus fenômenos linguísticos - em destaque neste trabalho a alternância das fricativas e africadas -, faz-se necessário apontar primeiramente o aporte teórico da Sociolinguística Variacionista presente na terceira onda, apresentando as abordagens sobre a língua/ linguagem/fala e as variações linguísticas presentes no cotidiano das pessoas que fazem parte de uma prática estilística.

\subsection{Pressupostos teórico-metodoló- gicos: algumas considerações sobre a Sociolinguística Variacionista e seu estudo sobre crenças e atitudes}

A Sociolinguística Variacionista emerge na década de 60 , tendo como representante notório o linguista estadunidense William Labov, que expôs para os pesquisadores em Linguística novas perspectivas sobre a heterogeneidade da língua, apresentando uma resposta/reação às correntes de abordagens estruturalistas e gerativistas da época.

A obra Padrões Sociolinguísticos, publicada por Labov (2008) em 1972, é tida como o marco de primazia da então recém-nascida área de estudo. Labov (2008) evidenciou a comunidade de fala, onde, em sua perspectiva, a língua funciona como componente primordial para a interação entre indivíduo e sociedade, sendo essa capaz de promover a variação social e estilística da língua.

Para Labov (2008), o estudo da língua se torna valoroso quando é percebida em seu contexto sócio histórico, uma vez que, as mudanças e estruturas linguísticas adquiridas por comunidades de fala são reflexos dos processos históricos e sociais que aquela comunidade atravessou. Assim, as mudanças linguísticas, para o autor, são causas dos falantes que vivem em comunidades que, todo o tempo, se transformam. Sobre a variação social e estilística da língua, Labov (2008, p. 313) descreve que,

A variação social e estilística da língua desempenha papel importante na mudança linguística? Por "social" entendo aqueles traços da língua que caracterizam vários subgrupos numa sociedade heterogênea; e por "estilística" as alternâncias pelas quais um falante adapta sua linguagem ao contexto imediato do ato de fala. [...] A variação social e estilística pressupõe a opção de dizer "a mesma coisa" de várias maneiras diferentes, isto é, as variantes são idênticas em valor de verdade ou referencial, mas se opõem em sua significação social e/ou estilística.

A Sociolinguística Variacionista se ramifica no Brasil, segundo Freitag (2017, p. 12), a partir da década de 80 , onde a variação social e estilística da língua é tomada como um fenômeno da língua, transformada por seus falantes que estão em uma determinada comunidade de fala, assim a abordagem no Brasil "[...] foca a comunidade de fala, entendida não como um grupo de falantes que faz uso dos mesmos traços linguísticos, mas como um grupo que compartilha dos mesmos valores associados aos usos da língua [...].”. 
Para uma melhor compreensão sociolinguística sobre os traços linguísticos que são manifestados por determinados grupos e/ou por comunidades de fala, há no Brasil os estudos de crenças e atitudes que fazem parte da terceira onda da Sociolinguística Variacionista.

Nesta conjuntura, é imprescindível para este trabalho apresentar a terceira onda e sua perspectiva que, de acordo com Eckert (2012, p. 94),

Whereas the first two waves viewed the meaning of variation as incidental fallout from social space, the third wave views it as an essential feature of language. Variation constitutes a social semiotic system capable of expressing the full range of a community's social concerns. And as these concerns continually change, variables cannot be consensual markers of fixed meanings; on the contrary, their central property must be indexical mutability. This mutability is achieved in stylistic practice, as speakers make social-semiotic moves, reinterpreting variables and combining and recombining them in a continual process of bricolagem [...].

Ainda segundo a autora, a partir dos acontecimentos sociais e históricos que ocorrem em determinada comunidade de fala, há a criação de características fonológicas, léxicas e/ou gramaticais que se destacam na fala dos indivíduos e significam na fala e na realidade deles. Essa ocorrência linguística é destacada por Eckert (2012, p. 94), "This is not an accidental event, but a continuous process in which linguistic features of all sorts are continually imbued with a variety of meanings."

$\mathrm{Na}$ tendência da terceira onda, observa-se a prática do falar no cotidiano de comunidades de fala, buscando compreender como foi a constituição da identidade e da persona de um indivíduo. As variações linguísticas que ocorrem significam-se na ter- ceira onda motivado pela prática estilística, no qual, segundo Veloso (2014, p. 1744), “[...] as pessoas vão associar os recursos linguísticos em questão a uma série de outros recursos existentes para a manifestação do estilo (como vestimenta, postura, entre outras coisas)".

É nesse ponto que o estudo de crenças e atitudes entra em funcionamento. Através da estilística, presente na terceira onda, é possível identificar as crenças de um indivíduo sobre determinado fenômeno - presente em sua fala ou da fala do outro -, correlacionando os fatores sócio históricos que, definitivamente, influenciam nos traços sociolinguísticos de uma comunidade de fala.

Desta maneira, o estudo de crenças associa os traços sociolinguísticos com os fatores sociais. Para Labov (2008, p. 176), crenças podem ser entendidas como "[...] um conjunto uniforme de atitudes frente à linguagem que são partilhadas por quase todos os membros da comunidade de fala, seja no uso de uma forma estigmatizada ou prestigiada da língua em questão."

0 estudo de atitudes permeia a sociolinguística e tem como intenção, como o próprio nome indica, captar as atitudes linguísticas - positivas e/ou negativas de um indivíduo - acerca de dados socioculturais e linguísticos de determinada comunidade de fala. Para Calvet (2002), as atitudes são demonstradas - inconscientemente - a partir de ações e sentimentos de informantes sobre a sua língua e/ou a língua do outro, influindo o comportamento linguístico do informante sobre a sua atitude sobre as variedades da língua. Para Lambert e Lambert (1972, p. 100), atitude é

Uma atitude é uma maneira organizada e coerente de pensar, sentir e reagir a grupos, problemas sociais ou, de modo mais geral, a qualquer acontecimento no ambien- 
te. Os componentes essenciais das atitudes são pensamentos e crenças, sentimentos e emoções, bem como tendências para reagir. Podemos dizer que uma atitude se forma quando tais componentes estão de tal modo inter-relacionados, que as tendências de reação e os sentimentos específicos se tornam coerentemente associados ao objeto da atitude.

Os estudos sobre crenças e atitudes visam contribuir com a Sociolinguística Variacionista e com as políticas linguísticas que são discutidas e tramitadas no Brasil e em seus estados, a partir de trabalhos que visem propiciar a conscientização e o respeito para com a fala do outro, uma vez que, segundo Cardoso (2015, p. 5), em uma percepção fundamental em seu livro, aponta logo de início que as “[...] avaliações sobre os usos linguísticos pode auxiliar em planejamentos de status quanto à reavaliação de estereótipos que caracterizam identidades locais e que sejam alvo de preconceito linguístico." e, no fim da sua obra Cardoso (2015, p. 119) finaliza afirmando que "[...] linguisticamente falando, nenhum dialeto pode ser legitimamente considerado melhor que as outras variedades da língua [...].”

A partir das reflexões apresentadas por Cardoso (2015), pode-se discorrer que o estudo de crenças e atitudes possibilita enxergar/aprender/compreender a riqueza e a heterogeneidade da língua no Brasil, proporcionando a compreensão e o respeito pelas diferenças linguísticas que ocorrem nas diversas comunidades, espalhadas pelo país.

\subsection{Baixada Cuiabana: constituição sócio-histórica e características na fala}

Em trezentos anos de história, a capital Cuiabá e as outras cidades que fazem parte da Baixada Cuiabana, carregam em suas raízes a evidência de processos culturais, sociais, históricos e linguísticos. Hoje, o espaço da Baixada Cuiabana é composto, por catorze municípios: Acorizal, Barão de Melgaço, Campo Verde, Chapada dos Guimarães, Cuiabá, Jangada, Nobres, Nossa Senhora do Livramento, Nova Brasilândia, Planalto da Serra, Poconé, Rosário Oeste, Santo Antônio do Leverger e Várzea Grande.

0 que hoje é definido como Baixada Cuiabana começa a ser constituído no ano de 1719 quando, às margens do Rio Coxipó que deságua no Rio Cuiabá, os bandeirantes paulistas - subordinados à capitania de São Paulo - oficialmente fundaram Arraial de Cuiabá. Os bandeirantes eram encarregados de explorar novas regiões, com o objetivo de estabelecer territórios e encontrar novas riquezas. Nessa região encontraram jazidas de ouro, o que levou o pequeno povoado a receber levas de bandeirantes, portugueses e paulistas à procura do ouro.

Dado o aumento do número de pessoas na região, em 1727 o povoado de Cuiabá é elevado à condição de vila - Vila Real do Senhor Bom Jesus de Cuiabá - e, em 1818, torna-se cidade. Com um número expressivo de moradores, em 1835, pela Lei Providencial no 19, Cuiabá passa a ser a sede da capitania portuguesa. Contudo, nesse mesmo período, o crescimento de Cuiabá e das outras cidades/comunidades que foram surgindo ao redor, tornaram-se inexpressivos. Segundo Lima (2018, p. 25), "Com a decadência da exploração do ouro, por volta de mais ou menos 1800, Cuiabá viveu, por muitas décadas, um período denominado "isolamento geográfico".

Desta maneira, o grau de isolamento que a comunidade possuiu por um determinado período de tempo, segundo Lima (2018), impediu o contato/assimilação com a língua do outro, o que possibilitou profundas mu- 
danças na forma de falar daqueles que ali se estabeleceram. Nesse processo, houve a ocorrência conveniente que proveu, naquela comunidade, conforme o passar das gerações, a reestruturação gramatical e fonética do falar, levando-a a ter marcas exclusivas da identidade daquelas personas, carregando em sua língua e em seu falar uma forma diferente e independente. Assim, pode-se compreender e apontar, segundo Cardoso (2015) que houve a prodigiosa evidência da força de adaptação e criação da linguagem humana.

A partir da política de integração nacional do governo federal intitulada 'Marcha para o Oeste' o crescimento na região da Baixada Cuiabana tornou a crescer.

Os imigrantes que aqui chegaram nas décadas de 1950, 1960 e 1970, impelidos pela "marcha para o oeste", incentivada pelo presidente Getúlio Vargas desde os anos quarenta, mobilizados pelo sonho e empresa espetacular de construção de Brasília durante o governo de $\mathrm{JK}$, seduzidos pelas políticas públicas de incentivo ao povoamento do Brasil Central e da Amazônia e encorajados pela pavimentação das rodovias BR-163 e BR-364, ambas ligando Cuiabá aos grandes centros do país, depararam-se com brasileiros falantes de um português singular, pouco conhecido fora do estado de Mato Grosso. (COX, 2005, p. 65).

Assim, durante a expansão da Baixada Cuiabana, os padrões de comportamento e os valores culturais do grupo dominante foram ao encontro do falar da Baixada Cuiabana que resistiu por um tempo, contudo, conforme afirma alguns pesquisadores, como Cox (2005), essa projeção está se alterando e, pouco a pouco está ocorrendo a mudança linguística.

Outro ponto a ser considerado é a ascendência cultural e simbólica do falar do grupo dominante sobre a comunidade de fala da Baixada Cuiabana, que prevalece por ser a maioritária e estar sobre papel de destaque na mídia, o que coloca o falar da Baixada Cuiabana como estereotipado. Atualmente, deve ser levado em consideração também, no que condiz a parte sociodemográfica, a implosão dos ires e vires da Baixada Cuiabana o que leva o aumento do contato com a língua do outro - predominante -, que, como indica Lima (2018), favorece a mudança linguística por implicações de estereótipos da fala da Baixada Cuiabana.

Para Cox (2005) e Lima (2018), as mudanças no falar da comunidade da Baixada Cuiabana estão sendo percebidas, a princípio, nos falares das crianças e jovens, o que aponta o acesso, o contato e a permeabilização da língua majoritária do outro, o que está induzindo a reestruturação fonológica e gramatical da Baixada Cuiabana, onde, apenas os mais adultos e idosos, permanecem com as características na língua.

Nesta conjuntura, para Cox (2005, p. 83), foi a partir da Marcha para o Oeste, com a vinda de migrantes de diferentes regiões brasileiras - principalmente das regiões sul e sudeste -, que os estereótipos do falar da Baixada Cuiabana começaram a surgir.

Os colonizadores que aqui aportaram nas últimas quatro décadas - oriundos principalmente das regiões sul e sudeste, que se representam e apresentam diante dos outros brasileiros como a parte esclarecida e desenvolvida da nação - tenderam a interpretar o mato-grossense nativo e suas diferenças culturais e linguísticas como má diferença, como defasagem, como falta, como atraso, como um momento já superado de sua própria história. Essa leitura justificava, assim, a boa intenção de promover o outro à maioridade cultural. 0 ocidente é sempre bem intencionado! Quer dizer, envergando as bandeiras do progresso e da civilização, os colonizadores transformam diferenças qualitativas em diferenças quantitativas. 
Não conseguem não hierarquizar, mais exatamente, inferiorizar a diferença. Não conseguem não desejar intervir na diferença. Se a diferença é a má diferença, então intervir na vida do outro é um imperativo moral categórico. Em nome da boa diferença, justifica-se matar a má diferença, justifica-se o etnocídio.

0 preconceito de alguns, que geram estereótipos, apontam o falar da Baixada Cuiabana como um falar inferior, vista como a incapacidade de falar corretamente a dita língua 'hegemônica' - considerada, por algumas pessoas como a mais elevada, audível e de elite. Em um artigo sobre a crioulização que ocorreu no Caribe, Lucchesi (2019, p. 250) aponta em um excerto sua visão sobre aqueles que infamam outras línguas através do preconceito e, aponta que "[...] o preconceito não consegue reconhecer o que pode ser visto como mais um milagre da criação humana."

\subsubsection{0 falar da Baixada Cuiabana}

0 falar da Baixada Cuiabana destacase por possuir características linguísticas diferentes quando há a comparação com outras variedades linguísticas do país. Em sua variedade, apresenta um falar ritmado e entonado, que enfatiza e realça determinadas palavras que aparecem em destaque.

O falar da Baixada Cuiabana denota também fenômenos como a alternância entre as consoantes fricativas e as africadas, o rotacismo e a retroflexão - como o 'R' caipira -, a tendência de monotongar ditongos crescentes e/ou decrescentes, a alternância de [ãw] e [õ], o não aderir a regra de concordância de gênero, entre outros fenômenos que marcam o falar das personas que se identificam como moradores efetivos da Baixada Cuiabana.

Segundo Cox (2005), a característica de fala da Baixada Cuiabana que sobressalta a audição é o fenômeno da alternância das consoantes fricativas e as africadas.

Dentre os aspectos fonológicos envolvendo as consoantes, a realização das fricativas palatais [ $\mathrm{S}]$ e [3] como as africadas [t $\mathrm{f}]$ e [dz], respectivamente, tem sido considerada a marca registrada do falar cuiabano e, não raro, usado como uma metonímia caricatural para designar a estranheza provocada pela variedade linguística aqui falada, a exemplo dos enunciados: (1) [ $\varepsilon \mathrm{kuja}^{1} \mathrm{banu}$ de ${ }^{1}$ t ape e $\left.{ }^{1} \mathrm{Kru} \int\right]$ "É cuiabano de tchapa e cruz."; (2) [ ${ }^{1}$ lauge de mo ${ }^{1}$ adze] "Larga de moadje!". (COX, 2005, p. 79).

De acordo com Lima (2018), a alternância entre as consoantes fricativas alveolares e as fricativas alveopalatais, caracterizadas como fricativas pré-palatais surdas [J] e sonoras [3], no falar da Baixada Cuiabana, são enunciadas como africadas surdas [t $\mathrm{t}]$ e sonoras [dz], o que nos leva a pronúncia de, como por exemplo, 'djente', 'djóia', 'thapeo' e 'tchave'.

Esse falar rico e marcado por características sociais, culturais e históricas, como mencionado no ponto anterior, tornou-se alvo de deboche de alguns migrantes que vieram para as terras mato-grossenses. A identidade linguística marcada pela alternância das consoantes fricativas e africadas da Baixada Cuiabana, como variantes de [t] e [d], [t $]$ e [dz], entre os outros fenômenos linguísticos, sofre estigma por pressões sociais, o que está levando a uma mudança no falar daqueles que carregam consigo essas marcas.

[...] entre os cuiabanos jovens, as africadas [t $]$ e [dz] estavam deixando de ser variantes das fricativas [ $\left.\int\right]$ e [3] para serem variantes das oclusivas dentais [t] e [d] seguidas contiguamente pela vogal [i]. Eles abandonavam formas como [t $\left.\int u v e\right]$ e [dzuke], mas incorporavam formas como [dzie] e [ $\left.\mathrm{t} \int \mathrm{ie}\right]$. Se do ponto de vista fonético, quer dizer, estritamente linguístico, são semelhantes, do ponto de vista sociolinguístico valem dife- 
rentemente. Como variantes de [S] e [3], [t $\left.\int\right]$ e [d3], respectivamente, revestem-se de uma aura negativa decorrente do processo de folclorização da essência, por assim dizer, do falar cuiabano no novo cenário sócio-econômico-cultural. (COX, 2005, p. 84).

As relações de força e poder das elites acometeram os moradores da localidade da Baixada Cuiabana ocasionando o estigma desta identidade linguística. 0 [t $\left.\int\right]$ e o [d3], comum para aqueles que ali moravam, passou a ser rotulado como uma marca feia, estranha e esquisita à audição dos novos moradores. Por isso, os estudos sociolinguísticos sobre as variações e mudanças linguísticas que ocorrem no falar da Baixada Cuiabana, em destaque a ocorrência das variantes de [ $]$ e [3], [t $]$ e [d3], devem ser evidenciadas e estudadas, para que haja políticas públicas que preconizem o respeito para com o comportamento linguístico da Baixada Cuiabana.

\section{Metodologia}

Este artigo é, segundo as perspectivas de pesquisa de Gil (2008), de abordagem qualitativa e apresenta em sua análise dados quantitativos, uma vez que, para se abordar as crenças e atitudes dos informantes universitários, fez-se necessário a tabulação de percentuais e números representativos que se originaram no teste aplicado.

Para inferir as crenças e atitudes dos informantes, utilizou-se como método de coleta de dados o teste de percepção de diferencial semântico adaptado da técnica conhecida como matched guise, para que os informantes avaliassem a fala do outro, mais precisamente, um trecho de fala de uma pessoa que nasceu e mora na Baixada Cuiabana, retirada de um programa televisivo regional $^{1}$, a qual possui intensas passagens

10 trecho está disponível no link: https://www. de alternância entre fricativas e africadas. Essa técnica - matched guise -, formulada por Lambert e Lambert (1972), propõe a identificação de atitudes inconscientes de informantes em relação à sua língua e/ou a língua do outro.

Esta pesquisa possuiu dois espaços sociais, linguísticos, geográficos e históricos do estado de Mato Grosso. 0 primeiro espaço é a Baixada Cuiabana e o segundo espaço é a cidade onde nasceram e moram os informantes desta pesquisa, a cidade de Juara, localizada na região norte do estado, caracterizada por Antenor Nascentes (1953), em seu mapa, como território incaracterístico, ou seja, uma localidade onde a linguagem não possui características próprias e/ou firmadas, dado o grande número de migrações que essa região possui/sofre até hoje.

Assim, o corpus foi constituído por doze informantes universitários nascidos na cidade de Juara - seis do sexo/gênero feminino e seis do sexo/gênero masculino - que possuem entre 18 e 28 anos. Todos os universitários estão vinculados à Universidade do Estado de Mato Grosso (UNEMAT), localizada na cidade de Juara, no estado de Mato Grosso (MT) e responderam o teste de percepção de diferencial semântico através da plataforma Google formulários. 0 objetivo para com os informantes foi o de compreender as crenças e atitudes acerca dos valores socioculturais linguísticos da Baixada Cuiabana.

\section{Resultados e análise dos dados}

Após obter todos os dados, foi possível quantificar as porcentagens das respostas dadas

youtube.com/watch?v=G5lfJyoNRhI. Como este estudo tem por objetivo buscar compreender como os informantes avaliam a fala do outro - o falar da Baixada Cuiabana - não apresentaremos a descrição da fala retirado de um programa televisivo regional. 
pelos informantes universitários juarenses, avaliando o grau de crenças e atitudes sobre o falar de uma pessoa que nasceu e mora na baixada cuiabana, tendo como perspectiva que "O lingüista que entra no mundo só pode concluir que o ser humano é o herdeiro legítimo da estrutura incrivelmente complexa que nós agora estamos tentando analisar e compreender." (LABOV, 2008, p. 18).

As nove perguntas apresentadas a seguir, que foram aplicadas no teste de percepção de diferencial semântico adaptado da técnica matched guise, assinalaram 5 possibilidades de resposta: concordo, concordo parcialmente, discordo, discordo parcialmente, nem concordo nem discordo.

Questão 1 - Ao perguntar se a pessoa do áudio era culta, verificou-se que as percepções penderam para o peso da discordância, as respostas foram: $16,6 \%$ concordaram; $8,4 \%$ concordaram parcialmente; $50 \%$ discordaram e $25 \%$ discordaram parcialmente.

\section{Gráfico 1}

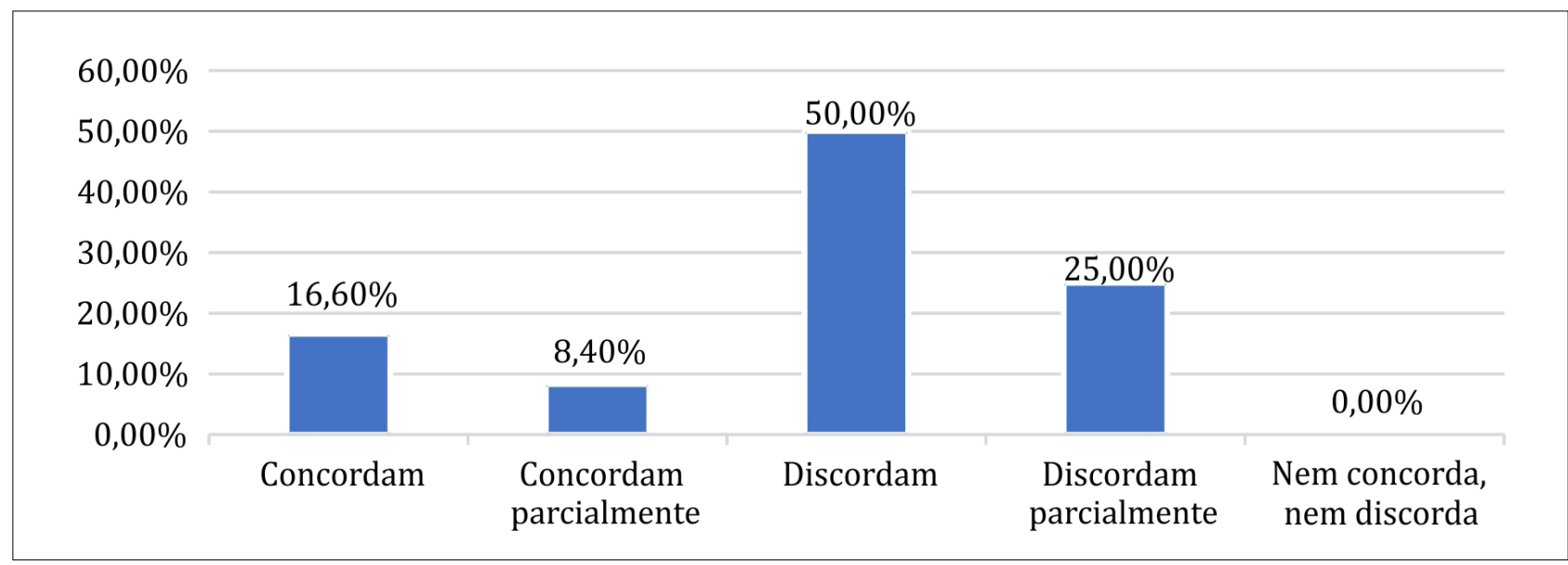

Questão 2 - Ao perguntar se a pessoa do áudio era simpática, $91,6 \%$ dos universitários qualificaram-na positivamente. As respostas foram: 50\% concordaram; $41,6 \%$ concordaram parcialmente e $8,4 \%$ discordaram.

\section{Gráfico 2}

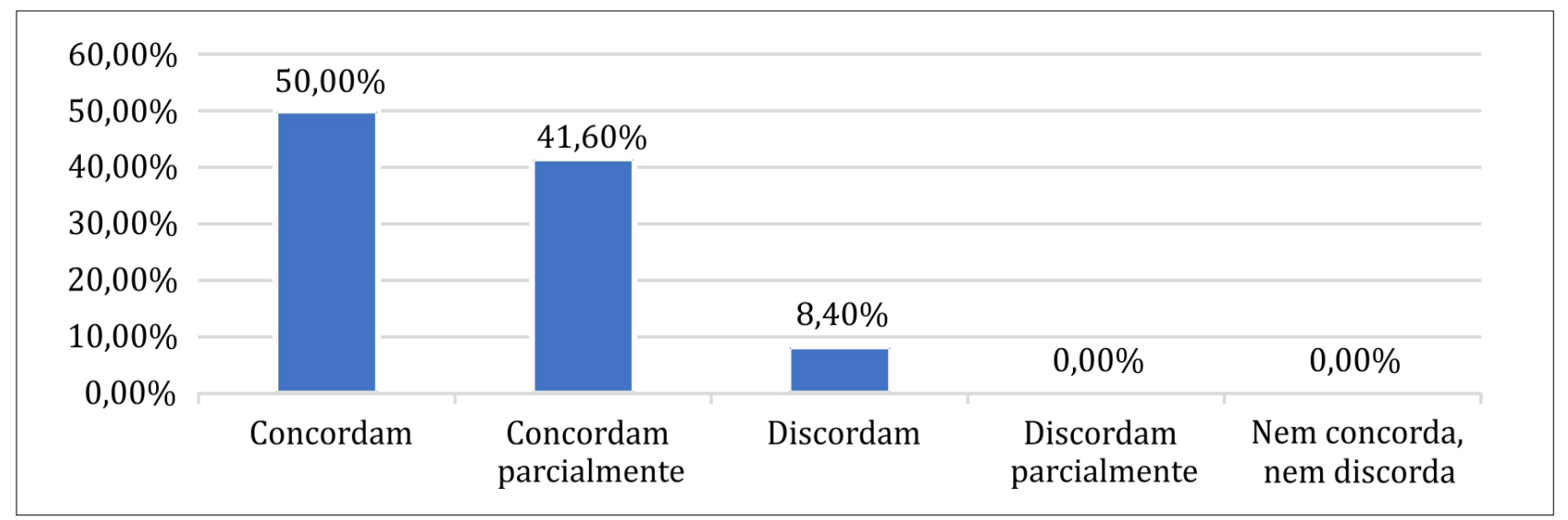


Questão 3 - Ao perguntar se a pessoa do áudio era humilde, obteve-se um nível de concordância maior do que a média, as respostas foram: $66,6 \%$ concordaram; $16,7 \%$ concordaram parcialmente e 16,\% nem concordaram nem discordaram - colocaram-se em posição de neutralidade.

\section{Gráfico 3}

\begin{tabular}{|c|c|c|c|c|c|}
\hline $7000 \%$ & $66,60 \%$ & & & & \\
\hline $60.00 \%$ & & & & & \\
\hline $50,00 \%$ & & & & & \\
\hline $40,00 \%$ & & & & & \\
\hline $30,00 \%$ & & & & & \\
\hline $20,00 \%$ & & $16,70 \%$ & & & $16,70 \%$ \\
\hline \multirow{3}{*}{$\begin{array}{r}10,00 \% \\
0,00 \%\end{array}$} & & & ค ००\% & $000 \%$ & \\
\hline & & & $0,00 \%$ & & \\
\hline & Concordam & $\begin{array}{l}\text { Concordam } \\
\text { parcialmente }\end{array}$ & Discordam & $\begin{array}{l}\text { Discordam } \\
\text { parcialmente }\end{array}$ & $\begin{array}{l}\text { Nem concord } \\
\text { nem discord }\end{array}$ \\
\hline
\end{tabular}

Questão 4 - Ao perguntar se a pessoa do áudio era urbana, percebeu-se que houve uma propensão maior à discordância, as res- postas foram: 16,7\% concordaram; 16,7\% concordaram parcialmente; $33,3 \%$ discordaram e $33,3 \%$ discordaram parcialmente.

\section{Gráfico 4}

\begin{tabular}{|c|c|c|c|c|c|}
\hline \multirow{2}{*}{$\begin{array}{l}35,00 \% \\
30,00 \%\end{array}$} & & & $33,30 \%$ & $33,30 \%$ & \\
\hline & \\
\hline \multicolumn{6}{|l|}{$25,00 \%$} \\
\hline $20,00 \%$ & & $16700 /$ & & & \\
\hline \multicolumn{6}{|l|}{$15,00 \%$} \\
\hline \multicolumn{6}{|l|}{$10,00 \%$} \\
\hline \multirow{3}{*}{$\begin{array}{l}5,00 \% \\
0,00 \%\end{array}$} & & & & & $000 \%$ \\
\hline & & & & & 0,0070 \\
\hline & Concordam & $\begin{array}{l}\text { Concordam } \\
\text { parcialmente }\end{array}$ & Discordam & $\begin{array}{c}\text { Discordam } \\
\text { parcialmente }\end{array}$ & $\begin{array}{l}\text { Nem concorda, } \\
\text { nem discorda }\end{array}$ \\
\hline
\end{tabular}

Questão 5 - Ao perguntar se a pessoa do áudio era confiável, avaliou-se que 66,6\% responderam em concordância, contudo o número de $25 \%$ de pessoas que se colocaram em neutralidade chamou atenção.
As respostas foram: $33,3 \%$ concordaram; $33,3 \%$ concordaram parcialmente; $8,4 \%$ discordou e $25 \%$ nem concordaram nem discordaram - colocaram-se em posição de neutralidade. 
Gráfico 5

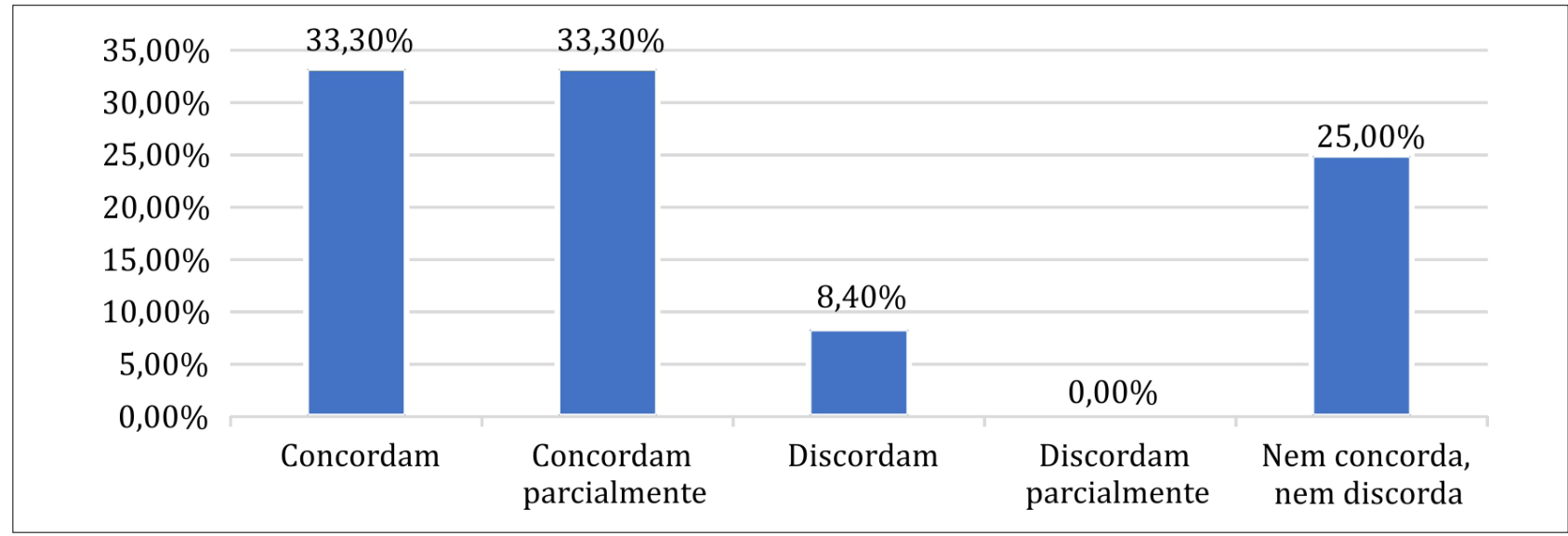

Questão 6 - Ao perguntar se a pessoa do áudio era moderna, obteve-se um número maior do que a média de discordância, as respostas foram: $16,6 \%$ concordaram par- cialmente; $66,6 \%$ discordaram; $8,4 \%$ discordaram parcialmente e $8,4 \%$ nem concordaram nem discordaram - colocaram-se em posição de neutralidade.

\section{Gráfico 6}

\begin{tabular}{|c|c|c|c|c|c|}
\hline $70,00 \%$ & \multicolumn{5}{|c|}{$66,60 \%$} \\
\hline \multicolumn{6}{|l|}{$60,00 \%$} \\
\hline \multicolumn{6}{|l|}{$50,00 \%$} \\
\hline \multicolumn{6}{|l|}{$40,00 \%$} \\
\hline \multirow{2}{*}{$30,00 \%$} & & & & & \\
\hline & & $16,60 \%$ & & & \\
\hline Z0,00\% & & & & $8,40 \%$ & $8,40 \%$ \\
\hline \multirow{2}{*}{$\begin{array}{r}10,00 \% \\
0,00 \%\end{array}$} & $0,00 \%$ & & & & \\
\hline & Concordam & $\begin{array}{l}\text { Concordam } \\
\text { parcialmente }\end{array}$ & Discordam & $\begin{array}{l}\text { Discordam } \\
\text { parcialmente }\end{array}$ & $\begin{array}{l}\text { Nem concorda, } \\
\text { nem discorda }\end{array}$ \\
\hline
\end{tabular}

Questão 7 - Ao perguntar se a pessoa do áudio não tinha escolarização as respostas foram: 50,20\% concordaram; $16,6 \%$ concordaram parcialmente; $16,6 \%$ discorda- ram parcialmente e 16,6\% nem concordaram nem discordaram - colocaram-se em posição de neutralidade.

Gráfico 7

\begin{tabular}{|c|c|c|c|}
\hline $60,00 \%$ & & & \\
\hline $50,00 \%$ \\
$40,00 \%$ \\
$30,00 \%$ \\
$20,00 \%$
\end{tabular}


Questão 8 - Ao perguntar se a pessoa do áudio possuía escolarização incompleta as respostas foram: $66,6 \%$ concordaram; $8,4 \%$ concordaram parcialmente; $8,4 \%$ discorda- ram parcialmente e 16,6\% nem concordaram nem discordaram - colocaram-se em posição de neutralidade.

\section{Gráfico 8}

\begin{tabular}{|c|c|c|c|c|c|}
\hline $7000 \%$ & $66,60 \%$ & & & & \\
\hline $60,00 \%$ & & & & & \\
\hline $50,00 \%$ & & & & & \\
\hline $40,00 \%$ & & & & & \\
\hline $30,00 \%$ & & & & & \\
\hline $20,00 \%$ & & & & & $16,60 \%$ \\
\hline \multirow{3}{*}{$\begin{array}{r}10,00 \% \\
0,00 \%\end{array}$} & & $8,40 \%$ & & $8,40 \%$ & \\
\hline & & & $0,00 \%$ & & \\
\hline & Concordam & $\begin{array}{l}\text { Concordam } \\
\text { parcialmente }\end{array}$ & Discordam & $\begin{array}{l}\text { Discordam } \\
\text { parcialmente }\end{array}$ & $\begin{array}{l}\text { Nem concorda, } \\
\text { nem discorda }\end{array}$ \\
\hline
\end{tabular}

Questão 9 - Ao perguntar se a pessoa do áudio possuía escolarização completa as respostas foram: $66,6 \%$ discordaram;
$16,7 \%$ discordaram parcialmente e $16,7 \%$ nem concordaram nem discordaram - colocaram-se em posição de neutralidade.

\section{Gráfico 9}

\begin{tabular}{|c|c|c|c|c|c|}
\hline $70,00 \%$ & \multicolumn{5}{|c|}{$66,60 \%$} \\
\hline \multicolumn{6}{|l|}{$60,00 \%$} \\
\hline \multicolumn{6}{|l|}{$50,00 \%$} \\
\hline \multicolumn{6}{|l|}{$40,00 \%$} \\
\hline \multicolumn{6}{|l|}{$30,00 \%$} \\
\hline \multicolumn{6}{|l|}{$20,00 \%$} \\
\hline \multirow{3}{*}{$\begin{array}{r}10,00 \% \\
0,00 \%\end{array}$} & & & & & \\
\hline & $0,00 \%$ & $0,00 \%$ & & & \\
\hline & Concordam & $\begin{array}{l}\text { Concordam } \\
\text { parcialmente }\end{array}$ & Discordam & $\begin{array}{l}\text { Discordam } \\
\text { parcialmente }\end{array}$ & $\begin{array}{l}\text { Nem concorda, } \\
\text { nem discorda }\end{array}$ \\
\hline
\end{tabular}

Nas perguntas referentes à escolarização da pessoa do áudio, percebeu-se que a maioria dos informantes universitários juarenses classificaram-na como uma pessoa que possui pouca escolarização ou nenhuma escolarização, discordando, em sua maioria, que a pessoa pudesse ter uma escolarização completa. Neste ponto, percebe-se que o falar da Baixada Cuiabana é estereotipado pelos informantes, apontan- do que a presente pesquisa está paripassu com outras pesquisas - como a realizada por Cox (2005) - que já foram realizadas sobre as percepções linguísticas do falar da baixada cuiabana.

Ao perguntar sobre a classe social da pessoa do áudio, os informantes responderam da seguinte forma: 58,3\% classificaram-na como pertencente da classe baixa; $41,6 \%$ da classe média e $0,0 \%$ da classe alta. 
No teste de percepção de diferencial semântico realizou-se também duas perguntas. Na primeira "Você se identifica com o modo de falar da pessoa do áudio?" percebeu-se que $100 \%$ dos informantes disseram que não, como se observa na Tabela 1 , o que leva a observação de que, por mais que os informantes tenham nascido e moram no mesmo estado da pessoa do áudio, os informantes não se identificaram com o falar da Baixada Cuiabana. 0 que retoma a explicação de Nascentes (1953), que caracteriza a região norte do Mato Grosso como território linguístico incaracterístico, ou seja, uma região que ainda não possui características linguísticas próprias - dado o grande número de migrações que essa região possui até hoje - diferentemente da linguagem constatada na região da Baixada Cuiabana, firmada por um longo período de tempo, mas que, atualmente está fenecendo, segundo Cox (2005).

Tabela 1

\begin{tabular}{|c|c|}
\hline In. $F^{2} \cdot 1$ & Não. \\
\hline In.M.2 & Às vezes. Nos momentos de descontração, imito algumas palavras típicas desse território. \\
\hline In.M.3 & Não, pois utilizo na maioria das vezes, uma linguagem mais formal. \\
\hline In.F.4 & Não. Por que não convivo com pessoas que falam dessa maneira. \\
\hline In.M.5 & Não. \\
\hline In.M.6 & Não. fala muitos palavrões que não conheço. \\
\hline In.M.7 & Não. Essa pessoa possui características de fala da região onde mora. \\
\hline In.F.8 & Não. Utilizo a linguagem comum. \\
\hline In.F.9 & $\begin{array}{l}\text { Não, acredito que as falas feita por essa pessoa do áudio possui grande influência do } \\
\text { estado em que vive. }\end{array}$ \\
\hline In.F.10 & $\begin{array}{l}\text { Não, o sotaque desta pessoa é bem diferente e as gírias são bem diferentes da cultura que } \\
\text { estou inserida }\end{array}$ \\
\hline In.F.11 & Não, pois nossa maneira de falar é diferente. \\
\hline In.M.12 & Não. Pelo fato da região dela e por onde ela vive. \\
\hline
\end{tabular}

Na segunda pergunta "Qual é o seu modo de falar?", constatou-se que dez informantes - do In.F.1 ao In.F.10 - caracterizam-se com termos como 'culto', 'formal', 'urbano', 'normal', 'popular' e 'comum', desenhando uma diferença do seu falar para com o fa-

2 In.F. = Informante do sexo/gênero feminino; In.M. = Informante do sexo/gênero masculino. lar do sujeito do áudio, o que aponta a estereotipação do falar da Baixada Cuiabana novamente, uma vez que, se o falar dos nascidos e moradores juarenses, repetindo, é caracterizado como, 'culto', 'formal', 'urbano', 'normal', 'popular' e 'comum', o falar da Baixada Cuiabana seria nomeada de qual forma? 
Tabela 2

\begin{tabular}{c|l}
\hline In.F.1 & Culto. \\
\hline In.M.2 & $\begin{array}{l}\text { Depende da ocasião. Se for um lugar, um momento que exige uma linguagem formal, faço o } \\
\text { uso. Já em momentos do dia a dia, uso de forma inconsciente e caio no vício de linguagem, } \\
\text { com algumas deficiências do usuário (eu). }\end{array}$ \\
\hline In.M.3 & Eu utilizo um modo mais formal, com algumas pequenas vezes a informal. \\
\hline In.F.4 & $\begin{array}{l}\text { Formal. Mas eu sei que o som do "r" é forte quando eu falo. Por ser do mato grosso acho } \\
\text { que está mais para a linguagem caipira. }\end{array}$ \\
\hline In.M.5 & Linguagem culta com um pouco de gírias. \\
\hline In.M.6 & Mais urbano, sem sotaques. \\
\hline In.M.7 & Normal. Com muita influência da cultura social. \\
\hline In.F.8 & Popular. \\
\hline In.F.9 & Normal. \\
\hline In.F.10 & Acredito que comum, com alguns erros de português, e algumas gírias do meu cotidiano. \\
\hline In.F.11 & Falo de acordo com o sotaque da região norte. \\
\hline In.M.12 & Juarense. Porque eu nasci em Juara. \\
\hline
\end{tabular}

Os universitários In.F.4, In.F.11 e In.M.12 responderam dando destaque ao modo de falar da região norte de Mato Grosso, que, como citado acima, é tomado por Nascentes (1953) como um território linguístico incaracterístico. 0 que leva a perspectivas de novos trabalhos sobre quais são as características linguísticas da cidade de Juara que, como citado pela In.F.4, possui a presença forte do rotacismo presente no 'dialeto caipira', que nos leva a questão - para futuros trabalhos - sobre o falar juarense.

Para finalizar, dadas as respostas dos informantes, verificou-se que houve a presença de estereótipos negativos voltados para a comunidade de fala da Baixada Cuiabana. Dessa forma, há a realização de um pré-julgamento do outro pelo seu modo e caracterização de fala, e isso ocorre sem ao menos saber quem é o sujeito, onde mora, quais suas relações culturais, econômicas, sociais e históricas. Em uma relação de força e poder a qual nosso país está submerso, a 'força/influência' de falar do grupo dominante - apresentado pelo contato real e/ou digital - estigmatiza o falar do outro e, consequentemente, estereotipa toda sua extensão cultural e histórica, levando-o a ser subjugado por um preconceito não só linguístico, mas também, social. 


\section{Considerações finais}

Neste artigo, procurou-se compreender as crenças e atitudes de universitários juarenses, sobre o falar de uma pessoa que nasceu e mora na Baixada Cuiabana, tendo como fenômeno teórico - em evidência na fala do sujeito - a alternância das fricativas e africadas. 0 teste de percepção de diferencial semântico adaptado da técnica matched guise, possibilitou analisar as percepções linguísticas dos informantes universitários juarenses, que teve como resultado a comprovação da hipótese levantada: os informantes universitários avaliariam a comunidade de fala da Baixada Cuiabana como uma variação linguística estigmatizada.

Percebeu-se que a estigmatização realizada pelos informantes universitários ocorreu não só em referência ao fator linguístico da pessoa que possui a característica do falar da Baixada Cuiabana, mas a partir do teste, percebe-se que há a presença de estigmas sociais, econômicos e culturais.

Nesta conjuntura, evidencia-se que o estereótipo e a propensa estigmatização da variedade de fala da comunidade da Baixada Cuiabana foi e ainda é um importante objeto de estudo e discussões dentro do campo da Linguística, o que leva a certeza de que, independentemente de quem são os informantes, ainda há a necessidade de mais trabalhos e atitudes políticas e educacionais referentes ao respeito para com o modo de falar de determinada comunidade linguística, ou seja, o modo de falar do outro.

\section{Referências}

BLOMMAERT, Jan; RAMPTON, Ben. Language and superdiversity. Diversities, v. 13, n. 2, p. 1-21, 2011. Disponível em: www.unesco.org/ shs/diversities/vol13/issue2/art1. Acesso em: 23 jul. 2019.

CALVET, Louis-Jean. Sociolingüística: uma in- trodução crítica. Tradução: Marcos Marcionilo. São Paulo: Parábola, 2002.

CARDOSO, Denise Porto. Atitudes linguísticas e avaliações subjetivas de alguns dialetos brasileiros. São Paulo: Blucher, 2015.

COX, Maria Inês Pagliarini. Quanto vale o falar cuiabano no mercado linguístico mato-grossense. In: COX, Maria Inês Pagliarini. (org.). Que português é esse? vozes em conflito. São Carlos e Cuiabá: Pedro \& João e EdUFMT, 2005.

ECKERT, Penelope. Three waves of variation study: the emergence of meaning in the study of sociolinguistic variation. Annual Reviews, v. 41, p. 87-100, 2012. Disponível em: https://www. annualreviews.org/doi/abs/10.1146/annurev-anthro-092611-145828. Acesso em: 24 jul. 2019.

FREITAG, Raquel Meister Ko. Documentação sociolinguística: coleta de dados e ética em pesquisa. São Cristóvão: Editora UFS, 2017. E-book. Disponível em: https://www.academia.edu/34264564/Documenta\%C3\%A7\%C3\%A3o_Sociolingu\%C3\%ADstica_Coleta_de_ Dados_e_\%C3\%89tica_em_Pesquisa. Acesso em: 23 jul. 2019.

GIL, Antonio Carlos. Métodos e técnicas de pesquisa social. 6. ed. São Paulo: Atlas, 2008.

LABOV, William. Padrões sociolinguísticos. Tradução: Marcos Bagno, Maria Marta Pereira Scherre, Caroline Rodrigues Cardoso. São Paulo: Parábola Editorial, 2008.

LAMBERT, William Wilson; LAMBERT, Wallace Earl. Psicologia social. 3. ed. Rio de Janeiro: Zahar Editores, 1972.

LIMA, José Leonildo. A alternância entre as fricativas e africadas, a alternância de [ãw] e [õ] final e o gênero gramatical: marcas do português arcaico no falar cuiabano? In: PHILIPPSEN, Neusa Inês; LIMA, José Leonildo. Diversidade e variação linguística em Mato Grosso. Cáceres: Editora UNEMAT, 2018.

LUCCHESI, Dante. Por que a crioulização aconteceu no Caribe e não no Brasil? Condicionamentos sócio-históricos. Gragoatá: revista dos programas de pós-graduação do Instituto de Letras da UFF, Niterói, v. 24, n. 48, p. 277-255, jan./abr. 2019. Disponível em: http://www. gragoata.uff.br/index.php/gragoata/article/ 
view/1251/773. Acesso em: 22 jul. 2019.

NASCENTES, Antenor. O linguajar carioca. 2. ed. Rio de Janeiro: Organizações Simões, 1953.

VELOSO, Rafaela. As três ondas da sociolinguística e um estudo em comunidades de práticas. In: CONGRESSO INTERNACIONAL ASOCIACIÓN DE LINGÜISTICA Y FILOLOGÍA DE AMÉRICA
LATINA: ALFAL, 17., 2014, Paraíba. Anais [...]. Paraíba: Ideia, 2014. p. 1740-1749. Disponível em: http://mundoalfal.org/CDAnaisXVII/anais. html. Acesso em: 25 jul. 2019.

Recebido em: 13/04/2021 Aprovado em: 10/08/2021 